\title{
Understanding and Promoting Clinical Reasoning in Chronic and Multimorbid Conditions: A Call for GPs and Healthcare Professionals
}

\author{
Marie-Claude Audétat ${ }^{1,2,3^{*}}{ }^{\circledR}$, Julia Sader ${ }^{1}{ }^{(0)}$, Sarah Cairo Notari², Claire Ritz ${ }^{2}$, \\ Nathalie Caire Fon ${ }^{3}$, Hubert Maisonneuve ${ }^{2}$, Katherine Blondon',5, Mathieu Nendaz ${ }^{1,5}$ (i)
}

${ }^{1}$ UDREM (Unit of Development and Research in Medical Education), Faculty of Medicine, University of Geneva, Geneva, Switzerland ${ }^{2}$ UIGP (Family Medicine Unit), Faculty of Medicine, University of Geneva, Geneva, Switzerland

${ }^{3}$ Family and Emergency Medicine Department, Faculty of Medicine, Université de Montréal, Montréal, Canada

${ }^{4} \mathrm{CIS}$ (Center of Interprofessional Simulation), Geneva, Switzerland

${ }^{5}$ Department of Medicine, Faculty of Medicine, University of Geneva, Geneva, Switzerland

Email: *marie-claude.audetat@unige.ch

How to cite this paper: Audétat, M.-C., Sader, J., Notari, S.C., Ritz, C., Fon, N.C., Maisonneuve, H., Blondon, K. and Nendaz, M. (2019) Understanding and Promoting Clinical Reasoning in Chronic and Multimorbid Conditions: A Call for GPs and Healthcare Professionals. Health, 11, 13381346.

https://doi.org/10.4236/health.2019.1110103

Received: July 13, 2019

Accepted: October 13, 2019

Published: October 16, 2019

Copyright $\odot 2019$ by author(s) and Scientific Research Publishing Inc. This work is licensed under the Creative Commons Attribution International License (CC BY 4.0).

http://creativecommons.org/licenses/by/4.0/

\begin{abstract}
Multimorbidity, defined as 2 or more chronic diseases, is of increasing importance for health professionals. Many factors are at play when it comes to multimorbidity, but we still know very little about how clinicians actually weigh up the different factors-medical, social, and psychological-to reach a particular course of action. Further research is therefore required to explore the ways in which clinical reasoning processes are involved in the follow up of patients suffering from multimorbidities, to highlight their potential risks of errors. A better understanding of these clinical processes will also enrich supervision of trainees and collaboration between healthcare professionals involved in primary care.
\end{abstract}

\section{Keywords}

Clinical Reasoning, Primary Care, Multimorbidity, Supervision

The more one studies the clinical expert, the more one marvels at the complex and multidimensional components of knowledge and skill that she or he brings to bear on the problem, and the amazing adaptability she or he must possess to achieve the goal of effective care. G. Norman [1] 


\section{Multimorbidity: What Do We Know about the Current Challenges?}

Multimorbidity, or co-occurrence of several chronic diseases, is of increasing importance for healthcare professionals [2] [3] [4]. According to recent studies, patients suffering from multi-morbidities represent $52.1 \%$ of the patients who consult their general practitioner (GP) in Switzerland compared to $52.9 \%$ in England. We can find similar figures in Canada (more than 50\% of patients) [5]. The prevalence increases with age and socioeconomic deprivation [6] [7]. The management of patients with multiple morbidities presents specific challenges to clinicians, as there is some evidence that patients with multimorbidity receive a lower quality of care than those with single diseases [8] [9]; for example, the multiplicity of medication, the contradicting applications of certain guidelines, the frequent medical tests and appointments which might impinge on the patient's quality of life [8] [9].

There is a large literature on the issues of multimorbidity, in relation to the patient, the healthcare system and the clinician. Multimorbidity can affect the patient's quality of life, or require complex multi-drug therapy treatment plan, including the management of side effects [10]. It can impact the healthcare system in terms of costs and allocation of resources [2] [11]. For the clinicians, researchers have explored implementing Shared Decision Making and interprofessional collaboration with the different specialists to ensure care continuity and coordination, as well as how to deal with the longitudinal uncertainty [12]-[18].

Studies have highlighted GPs' and Healthcare professionals' perceptions and experiences when it comes to such clinical challenges [19] [20]. Sinnott et al. published a systematic review on the perceptions of GPs on the clinical management of multimorbidity: results show that the problems may be classified into four domains: disorganisation and fragmentation of healthcare; inadequacy of guidelines and evidence-based medicine; challenges in delivering patient-centred care; and barriers to Shared Decision Making [21].

\section{What about GPs and Healthcare Professionals' Clinical Reasoning?}

Reasoning processes are intrinsically involved in these domains of specific difficulties. This is exemplified by the use of guidelines, which are "generally written for sole conditions" [22]; many doctors feel they need to be able to interpret guidelines in the context of individual patients. This will allow them to reach a compromise by following guidelines and accommodating patient factors, such as patient preferences or the patient's ability to tolerate medication [12]. Nevertheless, many of them think that this change comes in conflict with what is seen as the "best practice" and therefore may feel guilty when they don't enforce guidelines [20] [23].

Another example of reported difficulty lies in clinicians' response to the complexities of Shared Decision Making: GPs tend to employ a range of techniques 
including prioritization of the doctor's or the patient's agenda [3] [24], avoidance of decision-making [19], solely drawing on one's own personal experience [24], or using additional investigations to support a decision [25]. All these strategies may be worthwhile, but can also suffer from biases, leading to over- or underestimate the different components of the clinical situation, eventually resulting in flawed assessment and decision errors.

Papers relating more specifically to the theories on clinical reasoning barely refer to chronic or multimorbid conditions. Indeed, in medicine, "reaching the diagnosis" is often times treated as the goal of clinical problem solving [26]; given this perspective, there is a consensus in the literature about the concept of a dual process of reasoning playing simultaneously and involving an immediate, intuitive approach, and a more conscious, analytical one. The spontaneous solutions emerging from the intuitive process may be challenged by the analytical one: the data at hand are interpreted to assess their fit with each hypothesis, so that each hypothesis is verified and may be rejected, maintained, or further tested with the acquisition of additional clinical information until a diagnosis is reached [27] [28] [29] [30] [31].

Ilgen et al. have suggested different potential reasons leading to this focus on diagnostic clinical reasoning, such as the satisfaction of having successfully met the challenge to find the diagnosis, what they call the "aha feeling", or the fact that "making a diagnosis" is in itself a way to organise and structure one's thinking process [26]. It would be worthwhile to note, however, that this cognitive approach of the clinical reasoning processes may minimise or not give sufficient consideration to the potential role of the patient, of the other implicated healthcare professionals, of the context, and of the resulting interactions between them [32].

Even if research attempting to understand the nature of clinical reasoning has been under way for nearly four decades, we still know very little about how clinicians actually weigh up the many factors-medical, social, and psychological-to reach a particular course of action [1]. And this is particularly the case for the monitoring of multimorbid patients. Taking care of patients with multi-morbidities and the resulting longitudinal follow-up lead us to consider that clinical reasoning continues beyond diagnosis and also includes clinical reasoning processes regarding the selection of purposeful actions, (e.g. the choice of investigations or treatments,), the implementation of alternatives strategies (e.g. Shared Decision Making, collaborative reasoning with healthcare professionals, etc.), the monitoring and evaluation of the results [33].

An emerging literature relates to these processes, calling them therapeutic reasoning [32], or management reasoning [34]. Cook et al. recently tried to describe the key differences between diagnostic reasoning and management reasoning [35]: diagnostic reasoning can be established as correct or incorrect whereas in management reasoning, the answer often depends. Diagnostic reasoning is not influenced by the patient's values or preferences, which is not the case for man- 
agement reasoning. Diagnostic reasoning can often be done in isolation from the patient whereas management reasoning requires the involvement of patients and healthcare professionals. Diagnostic reasoning is assigned at a given point in time, whereas management reasoning requires ongoing monitoring and frequent adjustments. Diagnostic reasoning requires a definite range of solutions whereas management reasoning involves a dynamic interplay amongst people, systems, settings, and competing priorities [34] [35]. Table 1 is inspired from the articulation of the key differences noted by Cook et al. and exemplifies how these differences come into play during the care of patients suffering from multimorbidity.

\section{Current Implications for Teaching and Supervising}

Despite the recent studies, management reasoning remains less understood. In order to be able to identify the risks of errors or potential difficulties, we need to better understand the clinical reasoning processes of clinicians engaged in management reasoning. Studies, such as that conducted by Graber, showed that the most common cognitive problems involve faulty synthesis [36]. Premature closure, (i.e., the failure to continue considering reasonable alternatives after an initial diagnosis was reached), seems to be the single most common cause. Contrary to what one might think, faulty or inadequate knowledge is uncommon [36]. Our own research with physicians involved with multimorbid patients suggests that other difficulties of clinical reasoning may also arise in management reasoning, such as difficulties in prioritizing (i.e., difficulty in focusing on the clinical case's most important aspects, or difficulty in appropriately choosing when to ascribe significance to cues or data obtained during the encounter)

Table 1. Clinical reasoning and multimorbidity: main differences.

\begin{tabular}{|c|c|}
\hline Management reasoning (Cook et al., 2019) [35] & Multimorbidity \\
\hline In management reasoning, the answer often depends. & $\begin{array}{l}\text { - The reasoning aim is not to achieve a diagnosis but often to maintain stability to } \\
\text { promote the patient's quality of life. } \\
\text { - There is no "single best" choice of care plans or treatments in such complex } \\
\text { situations with multiple diseases and several potential actions and treatments. } \\
\text { This implies cognitive processes such as prioritization, problem articulation and } \\
\text { anticipation. }\end{array}$ \\
\hline $\begin{array}{l}\text { Management reasoning is influenced by patient's } \\
\text { preferences and values, logistical constraints, etc., and } \\
\text { requires the involvement of patients and healthcare } \\
\text { professionals. }\end{array}$ & $\begin{array}{l}\text { - Prioritization, problem articulation and anticipation need to be made within the } \\
\text { context of patients' preferences and values. } \\
\text { - This highlights the importance of sharing one's own reasoning in a collaborative } \\
\text { and constructive way with the patient (as an actor of change) and the healthcare } \\
\text { professionals involved. }\end{array}$ \\
\hline $\begin{array}{l}\text { Management reasoning requires ongoing monitoring } \\
\text { and frequent adjustments, and involves a dynamic } \\
\text { interplay among people, systems, settings, and } \\
\text { competing priorities. }\end{array}$ & $\begin{array}{l}\text { - Care plans are not stabilized, but subject to continuous adaptation depending on } \\
\text { changes in the prioritization of problems, goals achievement, or as a result of } \\
\text { co-occurring events or altering contexts. } \\
\text { - It is therefore crucial to keep in mind a dynamic and never-ending } \\
\text { representation of the clinical situation; this requires the clinician to permanently } \\
\text { question his/her reasoning in order to adapt it to the patient and his/her context. }\end{array}$ \\
\hline
\end{tabular}


or difficulties in building an overall picture of the clinical situation (i.e., failure to make connections between the different pieces of information, failure to integrate the patient's perspective and contextual factors to build a picture of the clinical situation and adjust his/her investigation or management plan) [27] [37]. Other results suggest that clinical inertia, (i.e., failure of clinicians to initiate or intensify therapy when indicated) might be a major problem, for example in the management of hypertension; this could be more prevalent in elderly patients [38].

The effort to understand these processes may also support clinical training and supervision. As a matter of fact, supervisors should focus not only on the results of learners' clinical reasoning, but also on the processes and the context at stake for a particular case [39] [40]. Multimorbid patients follow up makes the clinical reasoning supervision and teaching more challenging; more than often, trainees struggle to cope with complexity and uncertainty, trying to avoid cognitive overload, which could lead them to inefficiency, cognitive shortcuts and errors, and/or frustration [35]. Nevertheless, dealing with complexity is part of the competencies trainees have to acquire [41].

Clinical supervisors must therefore acquire an understanding of clinical reasoning coupled with strong pedagogical skills to be able to articulate their findings to their learners and foster the development of strong clinical reasoning processes [27] [42].

\section{Developing Collaborative Care amongst Health Care Professionals: A Response to the Challenges Ahead}

Patients with chronic or multimorbid conditions also make daily decisions for their self-management without support from their healthcare providers. This reality introduces an additional chronic disease paradigm: the patient-professional partnership, involving shared decisions, collaborative care and self-management education [43]. Facing the challenge of meeting the complex needs of patients and their families, "medical care must be transformed into a more proactive, holistic, and collaborative model" [44], involving patients and their relatives, as well as different healthcare providers in an interprofessional approach. This interprofessional approach could also include collaborative reasoning [45].

\section{Conclusion}

Current care conceptualizations suggest that challenging cases as the ones with multi-morbidities provide clinicians and healthcare professionals with opportunities for personal growth through collaboration with colleagues, allowing them to identify new solutions through innovations in practice [26] [46]. Both research and teaching have a lot to gain from fostering collaboration between different disciplines. In this perspective, methodology for future research should include GPs and healthcare professionals dealing with multimorbid patients as well as patients themselves. 


\section{Conflicts of Interest}

The authors declare no conflicts of interest regarding the publication of this paper.

\section{References}

[1] Norman, G. (2005) Research in Clinical Reasoning; Past History and Current Trends. Medical Education, 39, 418-427. https://doi.org/10.1111/j.1365-2929.2005.02127.x

[2] Excoffier, S., Paschoud, A., Haller, D. and Herzig, L. (2016) Multimorbidity in a Primary Care Setting. Revue Médicale Suisse, 12, 917-921.

[3] Bower, P., Macdonald, W., Harkness, E., Gask, L., Kendrick, T., Valderas, J.M., et al. (2011) Multimorbidity, Service Organization and Clinical Decision Making in Primary Care: A Qualitative Study. Family Practice, 28, 579-587. https://doi.org/10.1093/fampra/cmr018

[4] Starfield, B. (2001) New Paradigms for Quality in Primary Care. British Journal of General Practice, 51, 303-309.

[5] Montague, T., Gogovor, A., Aylen, J., Ashley, L., Ahmed, S., Martin, L., et al. (2017) Patient-Centred Care in Canada: Key Components and the Path Forward. Healthcare Quarterly, 20, 50-56. https://doi.org/10.12927/hcq.2017.25136

[6] Excoffier, S., Herzig, L., N'Goran, A.A., Deruaz-Luyet, A. and Haller, D.M. (2018) Prevalence of Multimorbidity in General Practice: A Cross-Sectional Study within the Swiss Sentinel Surveillance System (Sentinella). BMJ Open, 8, e019616. https://doi.org/10.1136/bmjopen-2017-019616

[7] Cassell, A., Edwards, D., Harshfield, A., Rhodes, K., Brimicombe, J., Payne, R., et al. (2018) The Epidemiology of Multimorbidity in Primary Care: A Retrospective Cohort Study. British Journal of General Practice, 68, e245-e251. https://doi.org/10.3399/bjgp18X695465

[8] Bartels, C.M., Kind, A.J., Everett, C., Mell, M., McBride, P. and Smith, M. (2011) Low Frequency of Primary Lipid Screening among Medicare Patients with Rheumatoid Arthritis. Arthritis \& Rheumatism, 63, 1221-1230. https://doi.org/10.1002/art.30239

[9] Lagu, T., Weiner, M., Hollenbeak, C., Eachus, S., Roberts, C.S., Schwartz, J., et al. (2008) The Impact of Concordant and Discordant Conditions on the Quality of Care for Hyperlipidemia. Journal of General Internal Medicine, 23, 1208-1213. https://doi.org/10.1007/s11606-008-0647-4

[10] Boyd, C., Darer, J., Boult, C., Fried, L.P., Boult, L. and Wu, A.W. (2005) Clinical Practice Guidelines and Quality of Care for Older Patients with Multiple Comorbid Diseases: Implications for Pay for Performance. The Journal of the American Medical Association, 294, 716-724.

[11] van den Akker, M., Buntinx, F. and Knottnerus, J.A. (1996) Comorbidity or Multimorbidity: What's in a Name? A Review of Literature. European Journal of General Practice, 2, 65-70. https://doi.org/10.3109/13814789609162146

[12] Solomon, J., Raynor, D.K., Knapp, P. and Atkin, K. (2012) The Compatibility of Prescribing Guidelines and the Doctor-Patient Partnership: A Primary CaremixedMethods Study. British Journal of General Practice, 62, e275-e281. https://doi.org/10.3399/bjgp12X636119

[13] Arora, N.K. and McHorney, C. (2000) Patient Preferences for Medical Decision Making: Who Really Wants to Participate? Medical Care, 38, 335-341. 
https://doi.org/10.1097/00005650-200003000-00010

[14] Politi, M.C., Dizon, D.S., Frosch, D.L., Kuzemchak, M.D. and Stiggelbout, A.M.J.B. (2013) Importance of Clarifying Patients' Desired Role in Shared Decision Making to Match Their Level of Engagement with Their Preferences. British Medical Journal, 347, f7066. https://doi.org/10.1136/bmj.f7066

[15] Reuben, D.B. and Tinetti, M.E. (2012) Goal-Oriented Patient Care-An Alternative Health Outcomes Paradigm. The New England Journal of Medicine, 366, 777-779. https://doi.org/10.1056/NEJMp1113631

[16] Smith, S., Soubhi, H., Fortin, M., Hudon, C. and O’Dowd, T. (2012) Managing Patients with Multimorbidity: Systematic Review of Interventions in Primary Care and Community Settings. British Medical Journal, 345, e5205. https://doi.org/10.1136/bmj.e5205

[17] Gensichen, J., Muth, C., Butzlaff, M., Rosemann, T., Raspe, H., de Cornejo, G.M., et al. (2006) The Future Is Chronic: German Primary Care and the Chronic Care Model-The Comprehensive Principles in the Proactive Treatment of the Chronically Ill. Zeitschrift für ärztliche Fortbildung und Qualitätssicherung, 100, 365-374.

[18] Braithwaite, R.S., Fiellin, D. and Justice, A. (2009) The Payoff Time: A Flexible Framework to Help Clinicians Decide When Patients with Comorbid Disease Are Not Likely to Benefit from Practice Guidelines. Medical Care, 47, 610-617. https://doi.org/10.1097/MLR.0b013e31819748d5

[19] Smith, S., O'Kelly, S. and O’Dowd, T. (2010) GPs' and Pharmacists' Experiences of Managing Multimorbidity: A 'Pandora's Box'. British Journal of General Practice, 60, 285-294. https://doi.org/10.3399/bjgp10X514756

[20] O’Brien, R., Wykey, S., Guthriez, B., Graham, W. and Mercer, S. (2011) An 'Endless Struggle': A Qualitative Study of General Practitioners' and Practice Nurses' Experiences of Managing Multimorbidity in Socio-Economically Deprived Areas of Scotland. Chronic Illness, 7, 45-59. https://doi.org/10.1177/1742395310382461

[21] Sinnott, C., Mc Hugh, S. and Browne, J. (2013) GPs' Perspectives on the Management of Patients with Multimorbidity: Systematic Review and Synthesis of Qualitative Research. BMJ Open, 3, e003610. https://doi.org/10.1136/bmjopen-2013-003610

[22] Steinman, M.A., Sudore, R.L., Peterson, C.A., Harlow, J.B. and Fried, T.R. (2012) Influence of Patient Age and Comorbid Burden on Clinician Attitudes toward Heart Failure Guidelines. The American Journal of Geriatric Pharmacotherapy, 10 , 211-218. https://doi.org/10.1016/j.amjopharm.2012.04.003

[23] Schuling, J., Gebben, H., Veehof, L.J.G. and Haaijer-Ruskamp, F.M. (2012) Deprescribing Medication in Very Elderly Patients with Multimorbidity: The View of Dutch GPs. A Qualitative Study. BMC Family Practice, 13, 56. https://doi.org/10.1186/1471-2296-13-56

[24] Marx, G., Pusche, K. and Ahrens, D. (2009) Polypharmacy: A Dilemma in Primary Care? Results of Group Discussions with General Practitioners. Gesundheitswesen, 71, 339-348. https://doi.org/10.1055/s-0029-1192004

[25] Fried, T.R., Tinetti, M.E. and Iannone, L. (2011) Primary Care Clinicians' Experiences with Treatment Decision Making for Older Persons with Multiple Conditions. Archives of Internal Medicine, 171, 75-80.

[26] Ilgen, J.S., Eva, K. and Regehr, G. (2016) What's in a Label? Is Diagnosis the Start or the End of Clinical Reasoning? Journal of General Internal Medicine, 31, 435-437. https://doi.org/10.1007/s11606-016-3592-7 
[27] Audétat, M.-C., Laurin, S., Dory, V., Charlin, B. and Nendaz, M. (2018) Diagnosis and Management of Clinical Reasoning Difficulties: AMEE GUIDE 117. Association for Medical Education in Europe (AMEE), Dundee.

[28] Schmidt, H. and Rikers, R. (2007) How Expertise Develops in Medicine: Knowledge Encapsulation and Illness Script Formation. Medical Education, 41, 1133-1139.

[29] Pelaccia, T., Tardif, J., Triby, E., Ammirati, C., Bertrand, C., Dory, V., et al. (2014) How and When Do Expert Emergency Physicians Generate and Evaluate Diagnostic Hypotheses? A Qualitative Study Using Head-Mounted Video Cued-Recall Interviews. Annals of Emergency Medicine, 64, 575-585. https://doi.org/10.1016/j.annemergmed.2014.05.003

[30] Norman, G., Monteiro, S., Sherbino, J., Ilgen, J., Schmidt, H. and Mamede, S. (2017) The Causes of Errors in Clinical Reasoning: Cognitive Biases, Knowledge Deficits, and Dual Process Thinking. Academic Medicine, 92, 23-30. https://doi.org/10.1097/ACM.0000000000001421

[31] Croskerry, P. (2009) A Universal Model of diagnostic Reasoning. Academic Medicine, 84, 1022-1028. https://doi.org/10.1097/ACM.0b013e3181ace703

[32] McBee, E., Ratcliffe, T., Picho, K., Schuwirth, L., Artino Jr., A.R., Yepes-Rios, A.M., et al. (2017) Contextual Factors and Clinical Reasoning: Differences in Diagnostic and Therapeutic Reasoning in Board Certified versus Resident Physicians. BMC Medical Education, 17, 211. https://doi.org/10.1186/s12909-017-1041-x

[33] Charlin, B., Lubarsky, S., Millette, B., Crevier, F., Audétat, M., Charbonneau, A., et al. (2012) Clinical Reasoning Processes: Unraveling Complexity through Graphical Representation. Medical Education, 46, 454-463. https://doi.org/10.1111/j.1365-2923.2012.04242.x

[34] Cook, D.A., Sherbino, J. and Durning, S. (2018) Management Reasoning: Beyond the Diagnosis. The Journal of the American Medical Association, 319, 2267-2268.

[35] Cook, D.A., Durning, S.J., Sherbino, J. and Gruppen, L.D. (2019) Management Reasoning: Implications for Health Professions Educators and a Research Agenda. Academic Medicine, 94, 1310-1316. https://doi.org/10.1097/ACM.0000000000002768

[36] Graber, M. (2005) Diagnostic Errors in Medicine: A Case of Neglect. The Joint Commission Journal on Quality and Patient Safety, 31, 106-113. https://doi.org/10.1016/S1553-7250(05)31015-4

[37] Audétat, M., Laurin, S., Sanche, G., Béïque, C., Caire-Fon, N., Blais, J., et al. (2013) Clinical Reasoning Difficulties: A Taxonomy for Clinical Teachers. Medical Teacher, 35, e984-e989. https://doi.org/10.3109/0142159X.2012.733041

[38] Gil-Guillén, V., Orozco-Beltran, D., Carratala-Munuera, C., Marquez-Contreras, E., Durazo-Arvizu, R., Cooper, R., et al. (2013) Clinical Inertia in Poorly Controlled Elderly Hypertensive Patients: A Cross-Sectional Study in Spanish Physicians to Ascertain Reasons for Not Intensifying Treatment. American Journal of Cardiovascular Drugs, 13, 213-219. https://doi.org/10.1007/s40256-013-0025-4

[39] Nendaz, M.R., Charlin, B., LeBlanc, V. and Bordage, G. (2005) Clinical Reasoning: from Research Findings to Applications for Teaching. Pédagogie Médicale, 6, 235-254. https://doi.org/10.1051/pmed:2005028

[40] Nendaz, M., Gut, A. and Perrier, A. (2005) Common Strategies in Clinical Data Collection Displayed by Experienced Clinician-Teachers in Internal Medicine. Medical Teacher, 27, 415-421. https://doi.org/10.1080/01421590500084818

[41] Frank, J., Snell, L., Cate, O., Holmboe, E., Carraccio, C. and Swing, S. (2010) Competency-Based Medical Education: Theory to Practice. Medical Teacher, 32, 638-645. https://doi.org/10.3109/0142159X.2010.501190 
[42] Audetat, M.-C., Dory, V., Nendaz, M., Vanpee, D., Pestiaux, D., Junod Perron, N., et al. (2012) What Is So Difficult about Managing Clinical Reasoning Difficulties? Medical Education, 46, 216-227. ttps://doi.org/10.1111/j.1365-2923.2011.04151.x

[43] Bodenheimer, T., Lorig, K., Holman, H. and Grumbach, K. (2002) Patient SelfManagement of Chronic Disease in Primary Care. The Journal of the American Medical Association, 288, 2469-2475. https://doi.org/10.1001/jama.288.19.2469

[44] Wagner, E.H. (1998) Chronic Disease Management: What Will It Take to Improve Care for Chronic Illness? Effective Clinical Practice, 1, 2-4.

[45] Blondon, K., Chan, K., Muller-Juge, V., Cullati, S., Hudelson, P., Maître, F., et al. (2017) A Concordance-Based Study to Assess Doctors' and Nurses' Mental Models in Internal Medicine. PLoS ONE, 12, e0182608. https://doi.org/10.1371/journal.pone.0182608

[46] Mylopoulos, M. and Regher, G. (2011) Putting the Expert Together Again. Medical Education, 45, 920-926. https://doi.org/10.1111/j.1365-2923.2011.04032.x 